\title{
OPTIMIZING THE ROLE OF INKING UNIT IN OFFSET PRINTING MACHINE
}

\section{OPTIMALISASI PERAN UNIT PENINTAAN PADA MESIN CETAK OFSET}

\author{
Juliandri $^{\mathrm{a}^{*}}$, Anton Hadiwijaya ${ }^{\mathrm{a}}$,Yessy Yerta Situngkir ${ }^{\mathrm{a}}$ \\ a Teknik Grafika, Politeknik Negeri Media Kreatif, Indonesia \\ *Email: Juliandri@gmail.com
}

\begin{abstract}
In-depth observations have been made on the printing process using the Heidelberg Speedmaster CD 102 machine. In this process, the ink unit becomes the biggest concern because of its role in the quality of the printout. Observations are made directly in the field on routine procedures carried out and discuss events in the field to identify problems and determine actions. The results of the study indicate that there are several things that must be improved related to the routine maintenance schedule, the technical setup of the inking unit and identification of potential problems as a reference for improving standard operations in the field.
\end{abstract}

\section{Keywords—Inking unit, offset printing machine, speedmaster machine}

\begin{abstract}
Abstrak - Telah dilakukan pengamatan mendalam terhadap proses cetak dengan menggunakan mesin Heidelberg Speedmaster CD 102. Pada proses tersebut, unit penintaan menjadi perhatian terbesar karena perannya yang terhadap kualitas hasil cetak. Pengamatan dilakukan secara langsung di lapangan terhadap prosedur yang rutin yang dilakukan dan mendiskusikan kejadian-kejadian dilapangan untuk mengidentifikasi masalah dan memumutkan tindakan. Hasil penelitian menunjukkan ada beberapa hal yang harus diperbaiki terkait dengan jadwal rutin perawatan, teknis penyetelan unit penintaan dan identifikasi potensi masalah sebagai rujukan perbaikan standar operasi di lapangan.
\end{abstract}

Kata Kunci-unit penintaan, mesin cetak ofset, mesin speedmaster

\section{PENDAHULUAN}

Kemajuan teknologi berperan aktif dalam perkembangan industri grafika, karena kemajuan teknologi membuat teknologi cetak yang ada pada industri grafika menjadi banyak berubah dari yang dahulu konvensional menjadi digital. Hingga pada saat ini segala sesuatu yang bersifat instan, 
mudah, cepat dan berkualitas sudah menjadi suatu keharusan di dalam memenuhi di setiap kebutuhan masyarakat, maka industri grafika di tuntut untuk dapat menghasilkan produk yang berkualitas dengan harga yang relative terjangkau. Begitu juga dengan media cetak, bagi perusahaan yang ingin selalu dapat bertahan, berkembang, dan maju memerlukan sistem informasi yang sesuai dengan kebutuhan dan kemajuan teknologi, terutama bagi perusahaan yang bergerak di bidang percetakan (Baumann, 2007). Mereka juga harus cepat mengolah media yang menghasilkan informasi untuk proses pengambilan keputusan yang cepat, tepat dan akurat dalam menyiapkan strategi-strategi yang baru. Kini semakin banyak media cetak yang bermutu tinggi. hal ini tidak lepas dari teknik cetak yang semakin maju (Chung \& Jensen, 2011).

Pada industri grafika mesin cetak merupakan alat yang sangat penting yang tidak dapat dipisahkan perkembanganya dengan perkembangan industri grafika itu sendiri. Hal ini dapat dimaklumi mengingat mesin cetak adalah merupakan alat utama yang digunakan dalam proses cetak. Oleh karena itu seiring dengan perkembangan industri grafika yang terus berkembang harus diiringi pula dengan perkembangan terhadap teknologi mesin cetak, khususnya mesin cetak offset yang merupakan teknik cetak paling banyak dipergunakan dalam perusahaan percetakan. Seperti diketahui bahwa pada mesin cetak ofset terdapat faktor - faktor yang mempengaruhi kualitas cetak, yaitu: sumber daya manusia, mesin, bahan, dan pra cetak (Baumann, 2007).

Maka dari itu penggunaan mesin cetak dalam hal ini perusahan percetakan harus berusaha sebaik mungkin dalam menggunakan mesin cetak sesuai dengan prosedur standar yang telah ditetapkan oleh pabrik pembuat mesin cetak. Baik itu proses sebelum cetak, saat cetak, maupun setelah cetak. Dalam menggunakan teknologi mesin cetak penanganan serta prawatan harus benar-benar diperhatikan agar dalam proses pencetakan nya sesuai dengan prosedur alur kerja yang ditentukan dan meminimalisir kendala-kendala yang dapat mempengaruhi kualitas hasil cetak. Operator mesin cetak bertanggung jawab terhadap mesin pada saat proses cetak maupun perawatan nya. Perawatan nya pun harus dilakukan secara baik dan benar agar kemampuan mesin cetak dapat menghasilkan kualitas cetak yang baik tetap terjaga (Moreira et al., 2018).

Ada beberapa faktor yang mempengaruhi kestabilan lapisan tinta, yaitu kinerja unit penintaan berjalan baik atau tidak, dalam hal ini perawatan pada unit penintaan sangat berperan penting dalam menjaga kondisi mesin agar tetap bisa mencetak dan menghasilkan cetakan sesuai kualitas hasil cetak terutama yang berkaitan 
dengan bahan baku tinta, konstruksi atau susunan rol-rol penintaan sangat berperan penting bagi kualitas hasil cetak, kondisi fisik rol tinta, penyetelan rol-rol tinta, serta perawatan terhadap tiap-tiap komponen pada unit penintaan. Unit penintaan adalah unit tempat tinta cetak yang akan didistribusikan ke acuan cetak/pelat. Pemberian tinta pada cetak ofset terdiridari beberapa macam rol dan makin banyak rol yang terdapat pada unit penintaan, pemberian tinta akan makin sempurna dan rata. Unit penintaan yang poripori rol karet nya tertutup tidak baik untuk pengalihan tinta, sebab dapat merusak pelat dan hasilya menjadi kurang tajam. Rol yang pori-pori nya tertutup menyebabkan permukaan rol menjadi lebih keras yang bergesekkan dengan pelat, hingga lama kelamaan bagian image pada pelat menjadi rontok/terkikis. Rol karet yang pori-pori nya tetapterbuka dengan baik untuk menyerap dan melepaskan tinta dan tidak merusak gambar. Adapun permasalahan lainnya yang dihadapi antara lain rol karet akan sulit untuk dibersihkan pada waktu akan mengganti warna, apalagi jikaselesai mencetak dengan tinta warna gelap dan akan mengganti dengan tinta warna muda, rol harus dibersihkan terlebih dahulu sampai tinta-tinta yang sebelumnya hilang (Bhoomkar, Likhite, \& Navale; Jašúrek, Vališ, Syrový, \&
Jablonovský, 2011; Södergård, Launonen, \& Äikäs, 1996)

Karena begitu pentingnya unit penintaan pada proses cetak maka pada penelitian ini kami melakukan kajian untuk menentukan proses perawatan unit penintaan yang efisien untuk mendukung proses cetak yang menjamin keberlangsungan perusahaan.

\section{METODE PENELITIAN}

Kami melakukan pengamatan produksi yang menggunakan mesin cetak Heidelberg CD 102 dan mengumpulkan datadata di PT. X. Pengumpulan data ini dilakukan dengan mengamati secara langsung alur kerja proses pencetakan di mesin Heidelberg CD 102 dari awalhingga akhir, serta memahami permasalahan yang terjadi dan cara mengatasinya. melakukan wawancara dan diskusi dengan pihak pihakyang berhubungan dengan bidang cetak di lokasi seperti supervior dan Operator cetak di PT. X.

\section{HASIL DAN PEMBAHASAN}

\section{Penyetelan Rol Unit Penintaan}

Penyetelan rol ini dilakukan bertujuan untuk menjaga tekanan antara rol tetapbaik karena mengingat penyaluran tinta sangat dipengaruhi dari tekanan rol-rol tersebut. Untuk melakukan penyetelannya dapat dilakukan dengan cara berikut: 
1. Penyetelan rol jilat tinta terhadap rol bak tinta Untuk melakukan penyetelan ini dilakukan dengan cara :

2. Masukkan tinta ke bak tinta secukupnya secara merata.

3. Lalu gerakkan rol jilat tinta menggunakan "inching" agar rol jilat menekan dengan rol bak tinta dan diamkan sesaat.

4. Lihat jejak rol jilat pada rol bak tinta, ukuran standar jejak seharusnya $4 \mathrm{~mm}$.

5. Jika jejak rol belum sesuai dapat mengatur kembali tekanan rol menggunakan sekrup baut pada sisi mesin dengan memutar searah jarum jam jika ingin menambah tekanan dan memutar berlawanan arah jarum jam jika ingin mengurangi tekanan.

Penyetelan rol jilat tinta terhadap distribusi

Untuk melakukan penyetelan ini dilakukan dengan cara :

1. Berikan tinta pada rol yang akan dilakukan penyetelan secukupnya.

2. Lalu gerakkan rol jilat tinta agar menekan dengan rol distribusi menggunakan "inching" dan diamkan sesaat.

3. Lihat jejak rol pelat pada rol disribusi, ukuran standar jejak seharusnya $4 \mathrm{~mm}$.

4. Jika jejak rol belum sesuai dapat mengatur kembali tekanan rolmenggunakan sekrup baut pada sisi mesin dengan memutar searah jarum jam jika ingin menambah tekanan dan memutar berlawanan arah jarum jam jika ingin mengurangi tekanan.
5. Penyetelan rol pelat tinta terhadap rol distribusi

Untuk melakukan penyetelan ini dilakukan dengan cara :

1. Copot terlebih dahulu rol pelat (1,2,dan 13), dan biarkan rol pelat yangpaling dalam (rol pelat 14) tetap terpasang.

2. Berikan tinta pada rol yang akan dilakukkan penyetelan secukupnya.

3. Lalu gerakkan rol pelat agar menekan dengan rol distribusi menggunakan "inching" dan diamkan sesaat.

4. Lihat jejak rol pelat pada rol disribusi, ukuran standar jejak seharusnya 5-6 mm

5. Jika jejak rol belum sesuai dapat mengatur kembali tekanan rolmenggunakan sekrup baut pada sisi mesin dengan memutar searah jarum jam jika ingin menambah tekanan dan memutar berlawanan arah jarum jam jika ingin mengurangi tekanan.

6. Dan lakukan kembali cara di atas untuk mengetahui tekanan rol pelatlainnya (rol pelat 1,2,dan 13) dengan terlebih dahulu memulai dari rolyang paling dalam.

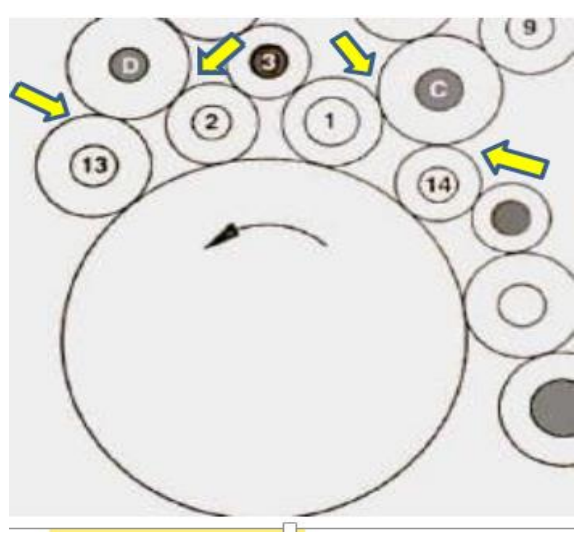

Gambar 1. Rol Pelat 
Penyetelan rol pelat terhadap silinder pelat Masalah yang timbul diantaranya sebagai Penyetelan ini dilakukan bertujuan untuk berikut:

mengetahui ukuran jejak rol pelat pada silinder pelat dengan cara :

1. Siapkan pelat dan pasang pelat pada silinder pelat.

2. Masukkan tinta ke bak tinta secukupnya.

3. Lalu jalankan mesin dan aktifkan unit penintaan penintaan pada mejakonsul agar tinta terbagi rata pada rol tinta.

4. Lalu aktifkan impression dan diamkan beberapa saat untuk melihat hasil jejak tinta.Perhatikan ukuran jejak tinta pada pelat dan ukur jejak tersebut yang seharusnya selebar 4-5 mm yang merata pada semua sisi rol.

5. Jika ada jejak tinta yang belum memenuhi ukuran 4-5 mm maka aturtekanan rol pada sisi yang ingin diubah (kanan atau kiri) dengan memutar sekrup pada sisi mesin, jika ingin menambah tekanan putar sekrup searah jarum jam dan jika ingin mengurangi tekanan tekan sekrup berlawanan arah jarum jam.

Mengingat pentingnya melakukan perawatan dan penyetelan pada unit penintan sesuai dengan standard yang sudah ditentukan karena jika tidak melakukan hal tersebut dapat mengakibatkan timbulnya masalah-masalah yang menggangu jalannya proses produksi cetak dan tentunya akan berpengaruh pada hasil kualitas cetak yang tidak maksimal.
1. Akibat kurangnya penanganan membersihkan rol tinta dapat berakibat tinta yang mengering/berkerak yang lama kelamaan akan terjadi endapan pada tepi rol tinta lalu beralih ke rol tinta sampai pada acuan cetak/pelat cetak. Masalah seperti ini dapat menimbulkan masalah pada cetakan yaitu noda berbentuk cincin yang muncul pada daerah hasil cetak atau disebut Hickeys. Jika terjadi masalah seperti ini dapat diatasi dengan cara :

2. Membersihkan sisi-sisi rol dari endapan tinta kering menggunakan bahan pencuci.

3. Membersihkan pelat menggunakan plate cleaner lalu bilas dengan air menggunakan spons.

4. Warna pada cetakan tidak merata akibat pendistribusian tinta antar rol tidak baik.

Jika terjadi masalah seperti ini dapat diatasi dengan cara :

1. Hentikan mesin terlebih dahulu.

2. Lakukan pemeriksaan dan penyetelan ulang tekanan pada rol-rolsesuai dengan standar yang ditentukan.

Rol transfer tinta tidak dapat menarik tinta dari rol distribusi. Masalah ini disebabkan karena kurangnya perawatan pada rol transfer tinta yang berakibat permukaan rol karet pori-pori nya tertutup. Jika terjadi masalah seperti ini dapat dilakukan 
penanganan dengan cara : Cuci rol transfer dengan menggunakan bahan kimia berupa wash benzine, rol o sov, atau yang sejenisnya sampai merata pada seluruh permukaan rol. Jika hal tersebut belum berhasil, lakukan perawatan rol tinta menggunakan rol o past dengan terlebih dahulu mencopot rol dari unit penintaan pada mesin lalu olesi permukaan rol dengan rol o past dengan ketebalan yang merata dan diamkan selama 24 jam agar kotoran yang mengendap benar-benar terangkat. Setelah 24 jam angkat kembali rol opast pada rol dan letakkan kembali di wadahnya agar bisa dipakai lagi. Cuci rol karet menggunakan air hangat dan keringkan menggunakan lap majong. Pasang kembali rol kemudian setel kembali tekanan antara rol sesuaistandar.

Masalah Cetak Yang Disebabkan Unit Penintaan dan Solusinya

(Ghosting) atau bayangan, ditandai dengan adanya warna tinta cetak yang lebih muda atau terang pada bagian warna tinta cetak yang solid (bagian image area). Masalah ini disebabkan oleh keseimbangan air dan tinta yang kurang baik (air terlalu banyak), dan penyetelan rol distribusi yang kurang baik. Jika terjadi masalah tersebut dapat dilakukan penanganan dengancara :

Kurangi air pembasah secukupnya.

Lakukan penyetelan ulang rol pelat terhadap rol distribusi tinta sesuai dengan standar.
Ganti tinta yang tidak terlalu transparan untuk cetakan solid.

(blocking) setelah kering cetakan menjadi lengket dan kertas terkelupas, apabila kertas dipisahkan dengan cara ditarik paksa kertas dapat sobek. Masalah ini disebabkan oleh tinta yang terlalu banyak/tebal, kertas menjadi menempel dengan kertas yang lainnya. Jika terjadi masalah tersebut dapat dilakukan penanganan dengan cara :

Mengganti jenis tinta yang sesuai dengan jenis kertas yang dipakai.

Mengatur penyuplaian tinta ke rol agar tidak terlalu banyak, sebab tinta yang berlebihan akan mengganggu proses pengalihan tinta dari rolpelat ke silinder pelat.

(trapping) kurang baiknya warna cetakan kedua diatas warna cetakan pertama, sehingga warna yang dihasilkan tidak maksmal. Ketidak seimbangan daya rekat dari tinta yang dicetak kedua lebih tinggi daripada tinta yang dicetak pertama. Jika terjadi masalah tersebut dapat dilakukan penanganan dengan cara :

Mengatur urutan tinta sesuai dengan daya rekat nya sesuai urutan, tintaberikutnya harus mempunyai daya rekat yang lebih rendah dari tinta yang pertama.

(tinting) warna tinta telihat pada bak air, dan pada bagian non imagemenjadi lapisan tinta tipis. Masalah ini disebabkan oleh pigment tinta yanglarut dalam air, tinta terlalu encer, keseimbangan air dan tnta kurang baik. Jika 
terjadi masalah tersebut dapat dilakukan sisi kiri sampai kanan, tekanan rol juga penanganan dengan cara :

Mengganti tinta yang sesuai.

Tambahkan compound pada bak tinta kurang lebih $10 \%$ dan aduk hingga tercampur rata dengan tinta.

Mengatur ulang volume air dan tinta pada meja kon

\section{KESIMPULAN}

Dari uraiaan tulisan ini, dapat disimpulkan sebagai berikut :

Kegiatan perawatan/pemeliharaan pada unit penintaan dilakukan secara berkala mulai dari perawatan harian, perawatan mingguan, dan perawatan bulanan. Kegiatan perawatan ini dilakukan yang bertujuan untuk menjaga kualitas komponen-komponen pada unit penintaan seperti rol-rol tinta, bak tinta, kondisi bearing pada rol, dan lainnya tetap berfungsi dengan baik dan memiliki masa pakai yang lebih panjang. Bahan-bahan untuk perawatan yang digunakan berupa Blue wash, rollfin, pastapur, dan roll opast.

Prosedur perawatan terhadap unit penintaan yang baik termasuk melakukan penyetelan unit penintaan yang akan mempengaruhi pada kualitas hasil cetak. Maka dari itu penyetelan unit penintaan dilakukan dengan cara yang baik dan benar. Hal-hal yang diperhatikan dalam penyetelan ini antara lain yaitu tekanan antar rol merata atau tekanannya sama dari disesuaikan dengan standar penyetelan rol agar peralihan tinta berjalan dengan baik.

Mesin cetak ofset lembaran merupakan mesin yang bisa dikatakan mempunyai komponen dan rangkaian mesin yang rumit, mesin sebagus apapun jika perawatan dan penyetelannya tidak dilakukan dengan benar maka akan tidak efisien penggunaannya dan akan merugikan banyak hal. Adapun masalah masalah yang timbul akibat kurang diperhatikannya perawatan dan penyetelan terhadap unit penintaan antara lain :

Permukaan rol karet pori-pori nya tertutup sehingga proses pengalihantinta antar rol tidak baik karena kurangnya perawatan terhadap rol. Hickeys yang disebabkan karena kurang diperhatikannya perawatanterhadap rol tinta dari endapan kotoran.

Ghosting yang disebabkan karena penyetelan tekanan rol pelatterhadap silinder pelat yang tidak baik.

\section{Trapping}

\section{Tinting}

Masalah-masalah tersebut disebabkan karena kurang diperhatikannya prosedur perawatan dan penyetelan terhadap unit penintaan, karena hal tersebut merupakan hal yang sangat penting untuk dilakukan, mengingat perawatan adalah suatu maintenance yang menunjang agar kualitas hasil cetakan baik 
dan seperti yang diinginkan serta mesin itu sendiri dapat beroperasi secara maksimal.

\section{REFERENSI}

Baumann, R. R. 2007. Industrial Printing Beyond Color. Paper presented at the NIP \& Digital Fabrication Conference.

Bhoomkar, M., Likhite, P., \& Navale, L. Experimental Investigation And Modification In Inking Rollers Of Offset Printing To Achieve $\mathrm{Wcm}$ Approach In Smpi.

Chung, R., \& Jensen, S. 2011. Printing standards: a 2010 survey report.

Jašúrek, B., Vališ, J., Syrový, T., \&
Jablonovský, B. 2011. Study of Rheological Properties and Tack of Offset Printing Inks. International circle Issue(4), 18-23.

Moreira, A., Silva, F., Correia, A., Pereira, T., Ferreira, L. P., \& De Almeida, F. (2018). Cost reduction and quality improvements in the printing industry. Procedia manufacturing, 17, 623-630.

Södergård, C., Launonen, R., \& Äikäs, J. (1996). Inspection of colour printing quality. International journal of pattern recognition and artificial intelligence, 10(02), 115-128. 